\title{
THE ENRICHMENT OF LEAN PRACTICES IN AN ASSEMBLY LINE BY APPLYING CONTINUOUS IMPROVEMENT METHODS
}

\author{
Aravinth Kumar A \\ Assistant Professor, VELS Institute of Science, \\ Technology and Advanced Studies, Chennai, 600117, \\ India
}

\begin{abstract}
The aim of this work is to standardize the assembly line in terms of working procedure, assembly sequence and operating time for every process which has value addition. To satisfy the targeted customer demand in the axle line production process and find the required resources to meet those demands. To achieve this prime goal, basic lean principles was established with the assistance of (Value Stream Mapping) VSM for finding the faults and elimination of wastages in the shop floor area by providing effective team formation, line selection, exact selection of product, conceptual designing, and time-frame formulation through production takt time calculation. The VSM focuses on all areas of the selected assembly line of the firm which adds value to a product as an output.
\end{abstract}

Keywords - Lean Manufacturing; Value Stream Mapping; Assembly line.

\section{INTRODUCTION}

Tomas Rohac et al. (2015) in their paper quoted that the lean administration incorporates a lot of devices that enable organizations to get solid advantages when they actualize them appropriately. The utilization of lean devices is a straightforward way and minimal effort answer for accomplishing efficiency and benefit, utilizing a persistent spotlight on the end of waste through all the association [3]. J.Oliveira et al. (2017) in their work tells that Lean Tools are anything but difficult to utilized instruments, they connect all the association and guarantees the dedication of all from top to down, they guarantee are an approach to enable the teammates and turn unmistakable every one of the aftereffects of their work. Lean's motivation is to create basic abilities and capabilities in associations. New inventive items and administrations want our associations, new basic learning is vital [1]. Jafri Mohd Rohani et al. (2015) in their project work they build up a worth stream map for a shading industry to decide and dispense with the squanders that didn't enhance the last item. It additionally intended to diminish lead time and

\author{
Rajenthirakumar D \\ Professor, Department of Mechanical Engineering, \\ PSG College of Technology, Coimbatore, 641004, \\ India
}

worth added time to expand the all-out throughput. In view of future VSM, conclusive outcome demonstrated that by executing some lean assembling systems, for example, 5S, Kanban strategy, Kaizen, etc Production Lead-time (PLT) diminished from 8.5 days to 6 days, and the worth included time diminished from 68 minutes to 37 minutes [4]. Rahul Adepu et al. (2015) in their paper they pointed out the principle point of study is to diminish the lead time by lean instruments. With the correct execution of lean instruments the issues can be understood successfully and the efficiency can be expanded. The paper examines about the examination and usage of lean apparatuses for lead time decrease. The focal point of study is to improve the general hardware adequacy and to fulfill the client need by utilizing standard working system and line adjusting procedures. Worth stream mapping (VSM) is a strategy that was initially created by Toyota [8]. Aravinth Kumar A et al. (2016) addressed that VSM is utilized to discover squander in the worth stream of the item. When lean waste is distinguished, it is simpler to make possible arrangement to dispose it off and the motivation behind VSM is process improvement at the framework level.VSM appears in ordinary stream design. Be that as it may, notwithstanding the data stream important arrangement and satisfy the client's need [9]. Satish Tyagi et al. (2014) convened that the Value Stream Mapping based technique is utilized to build up the present state map so as to discover the losses all the while and activity intend to kill every one of the losses to arrive at the future (better) state. So as to build up the present express, a Gemba walk is done so as to locate the most mind-boggling and protracted lead-time procedure focused on development. Therefore, a meeting to generate new ideas is directed to discover the main drivers of squanders. The structure is still in the usage stage, be that as it may, the normal advantages are condensed [10]. Aravinth Kumar A et al. (2016) in their pump industry case study they discussed about the effective utilization of VSM Process, the lead time and Inventory has been greatly reduced, further the Continuous flow was created wherever possible in the flow process [12]. 


\section{International Journal of Engineering Applied Sciences and Technology, 2019 Vol. 4, Issue 7, ISSN No. 2455-2143, Pages 382-385 \\ Published Online November 2019 in IJEAST (http://www.ijeast.com)}

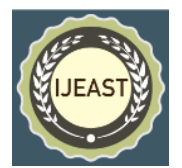

\section{LITERATURE REVIEW}

Parthasarathy Garre et al. (2017) in their research work steps were taken to improve the productivity of the pressure vessel manufacturing unit by creating a better organized system by implementing $5 \mathrm{~s}$ which reduced the motions and waits and also provided a better working environment. Dead inventory escalation was also performed as a part of $5 \mathrm{~s}$ to remove the scrap and other unnecessary raw materials An additional worker was employed at the full welding station to perform the pre weld jobs, to reduce the unnecessary waiting. All the wastes were identified and classified according to the lean methodology and appropriate tools were used to eliminate them [2]. Venkataraman K et al. (2014) specifically mentioned that the Value Stream Mapping based method is used to develop the current state map in order to find the wastes in the process and action plan to eliminate all the wastes to reach the future (better) state. In order to develop the current state, a Gemba walk is done in order to find the most complex and lengthy lead-time process targeted for improvement. Consequently, a brain storming session is conducted to find out the root causes of wastes. A framework exploiting the knowledge generated during process walk to store, retain and re-use is a potential research domain. In addition, the extension of VSM implementation on other critical process and finally to whole enterprise will be targeted in the future [5]. Neha Verma et al. (2017) in their case study, work has been done on identifying the waste related areas as a study of lean manufacturing. It has been found that the reason for nonvalue added activities are due to wrong handling material, long distance, defect and improper inventory. After literature study in the field of lean tools we concluded that the VSM is an effective tool for eliminating these wastes and study also suggested the ways to reduce non value added times in a manufacturing process [7]. Adwait Deshkar et al. (2018) in their paper outlined a framework to implement Lean Manufacturing using VSM in a small scale industry. Current state map of the company helped to identify different wastes in the selected value stream. The wastes were idleness, underproduction, unwanted WIP, high TAKT times, lack of pull and proper scheduling. Simulation of current state map provided insights into root causes of the wastes. VSM tools were utilized to eliminate non value adding activities and create future state map. Percentage of value added time in the total lead time increased from $15 \%$ to $89.85 \%$. TAKT time was reduced from $46.6 \mathrm{~min}$ to $26 \mathrm{~min}$. Number of rolls made increased to 50 per day [6]. Satish Tyagi et al. (2014) in their work the VSM framework is still in the implementation phase; however, the expected benefits are summarized in their study. All the proposed changes resulted in the reduction of lead time for the design stage reduces the overall PD lead time by $50 \%$ [10]. Aravinth Kumar A et al. (2018) wrapped up the successful VSM implementation followed by the time study, the more time consumption has been reduced in all the possible processes, further the material movement was streamlined. Complex steps and sequences were identified with the help of VSM and time study then the collected data can be used for improvement of the process in many ways [11].

\section{CASE STUDY}

The study was conducted in medium scale industry located in south india. The Work study technique involves the coverage of $100 \%$ of process stages in both the production line and a Minimum of 8 sample study (ILO standard) where different operators were Involved and was captured in different working days. The main framework is to study the Current State Value Stream Mapping by collecting the data further to identify the problems faced by the Industry assembly line in terms of Non Value Added time and activities and then to propose feasible Future State Value Stream Mapping which can increase the Value added time and reduce non value added time.

\section{METHODOLOGY \&WORK ANALYSIS}

It involves Time \& method study where we have Splitter of each stage process description into minimal work elements. The realization of measuring point for time study consideration was formed. Observation study of processing time for each operation was carried out by neglecting special cause delays with the estimation of Cycle time for each process stage (Average, Min \& Max).

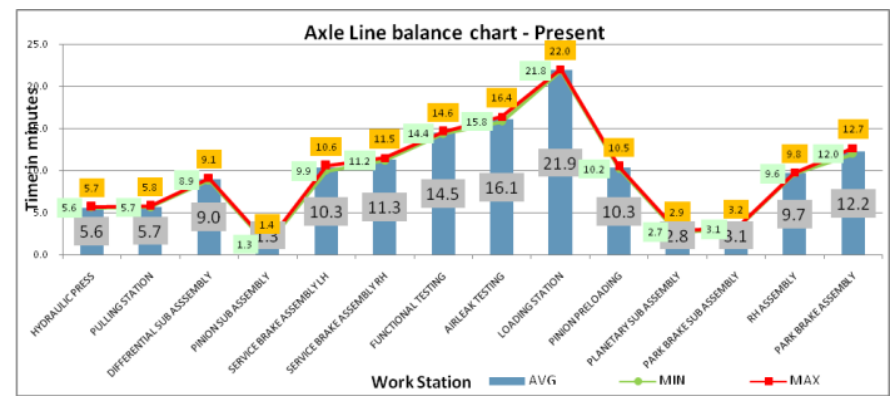

Fig1: Present Line balance chart - Axle line

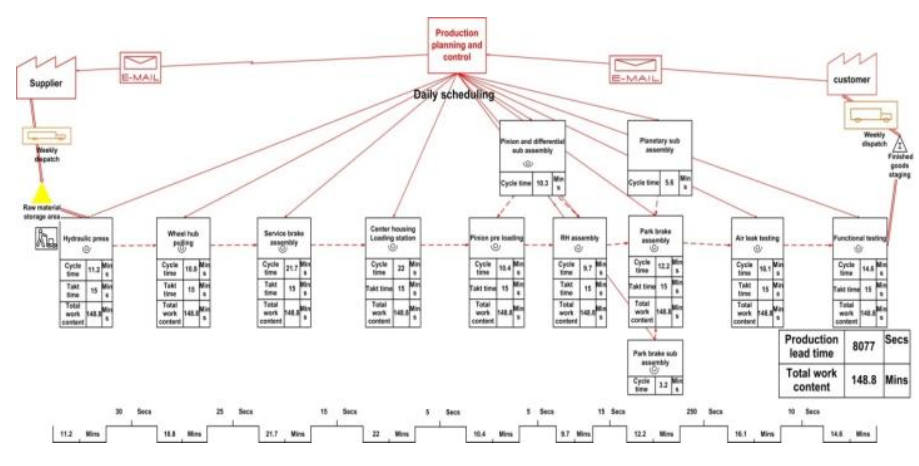

Fig 2: Value stream mapping - Axle assembly line (AS-IS Diagram) 


\section{International Journal of Engineering Applied Sciences and Technology, 2019 \\ Vol. 4, Issue 7, ISSN No. 2455-2143, Pages 382-385 \\ Published Online November 2019 in IJEAST (http://www.ijeast.com)}

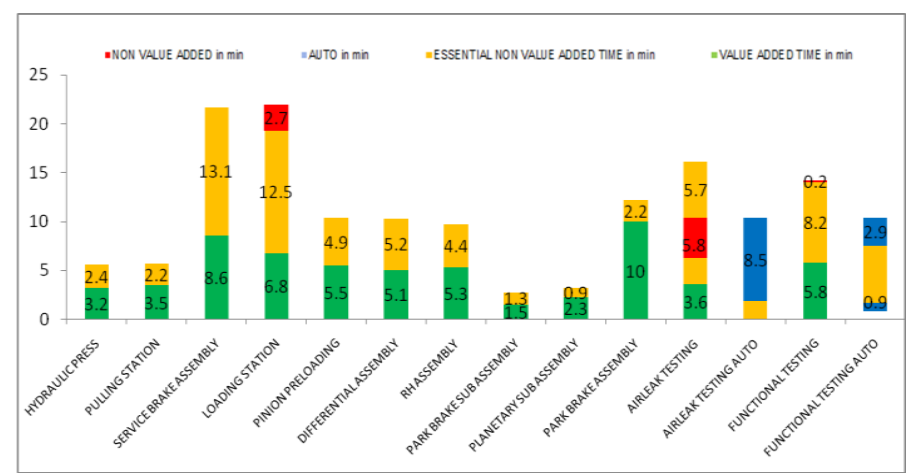

Fig 3: Value analysis chart

\section{IMPROVEMENT ACTIVITIES - AXLE LINE}

Sub assemblies of service brake assembly will be done in this Service brake station continuously. Low cost automation has been developed by the Implementation of Hydraulic tool for piston pressing in that process and further Equipments re-alignment, introducing an intermediate kitting trolley, part trolley, etc. In the Loading station the Cart picking process was distributed to Wheel hub assembly station and the Name plate typing process distributed to Pinion pre-loading station. Over there in the Pinion pre-loading station the Pinion bearing pressing \& name plate engraving process received from Differential Assembly station. Dedicated rack was provided for parts storage at work station where the Automation of Yoke \& screen sheet pressing process takes place with the available resources with no extra investment. In the Differential sub assembly process the Pinion bearing pressing operation transferred to Pinion pre loading station and also planetary sub assembly merged with this station. In Planetary sub assembly \& Park brake sub assembly stations merging of Park brake sub assembly process with Air leak testing station. Further merging of planetary sub assembly process with Differential assembly station. In the Park brake assembly and Air leak testing station the Preparation activities for air leak testing will be shifted to the park brake assembly station, also a bin will be used to take the required child parts from the material rack which reduces the worker movement in that place.

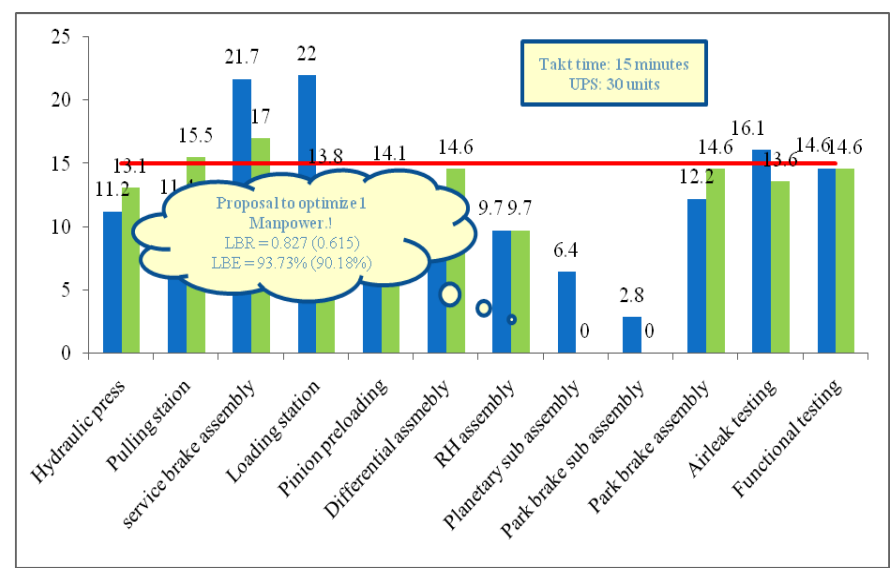

Fig 4: Target line balance - Axle assembly line

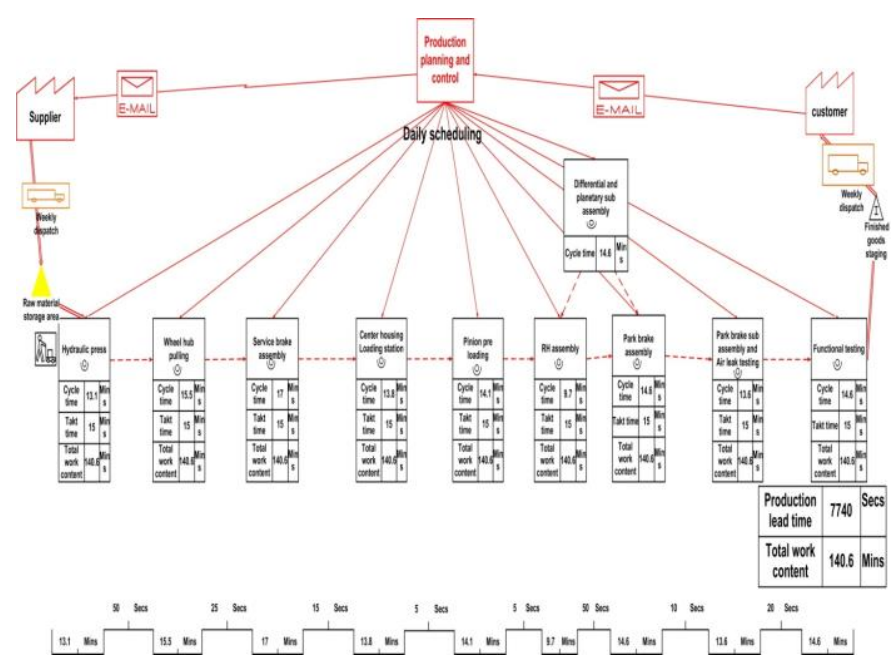

Fig 5: Value stream mapping - Axle assembly line (TO-BE Diagram)

\section{RESULTS AND DISCUSSIONS}

Due to the effective lean tools implementation the Man hours was saved a lot. Following that Waste elimination takes place in various areas, as much ENVA has been Reduced, possible areas equipped with Automation for critical \& poor ergonomic processes, Improved process flow for all models was developed, Modified process layout enabled in both the lines, Optimization of available tools which reduced the investment needs.

Table 1: Comparison of Present and Proposed Axle Line

\begin{tabular}{|l|l|l|}
\hline Description & Present - Axle line & Proposed - Axle line \\
\hline Total Work content (minutes) & 148.8 & 140.6 \\
\hline Production per shift (units) & 24 & 27 \\
\hline Manpower utilized & 11 & 10 \\
\hline Manpower required & 10 & 10 \\
\hline LBR (ratio) & 0.615 & 0.827 \\
\hline LBE (\%) & $90.18 \%$ & $93.73 \%$ \\
\hline Productivity & 2.18 & 2.7 \\
\hline
\end{tabular}

\section{CONCLUSION AND FUTURE WORK}

This work discusses the objective and associated problems with the assembly line process for a case study unit of an automotive manufacturer and delivers the possible outcomes with major improvements. The improvements of the project were completed by saving unwanted time, waste elimination and modification in layout. Moreover greater number of lean practices was followed in the assembly line and as many improvements were made in the shop floor and also several possible suggestions was given to the axle line and the benefit comparison before and after were discussed. 


\section{International Journal of Engineering Applied Sciences and Technology, 2019 \\ Vol. 4, Issue 7, ISSN No. 2455-2143, Pages 382-385 \\ Published Online November 2019 in IJEAST (http://www.ijeast.com)}

VIII. REFERENCE

[1] J.Oliveira, Sa J.C , Fernandes A (2017), “Continuous improvement through Lean Tools": An application in a mechanical company, Procedia Manufacturing 13, 1082-1089.

[2] Parthasarathy Garre, Nikhil Bharadwaj V.V.S, Shiva Shashank P (2017), "Applying lean in aerospace manufacturing" Materials Today: Proceedings 4,84398446.

[3] Tomas Rohac, Martin januska (2015), "Value stream mapping demonstration on real case study" Procedia Engineering 100, 520 - 529.

[4] Jafri Mohd Rohani, Seyed Mojib Zahra (2015), "Production line analysis via value stream mapping: a lean manufacturing process of color industry" Procedia Manufacturing 2, 6-10.

[5] Venkataraman K, Vijaya Ramnath B , Muthu Kumar V(2014), "Application of Value Stream Mapping for Reduction of Cycle Time in a Machining Process" Procedia Materials Science 6, 1187 - 1196.

[6] Adwait Deshkar, Saily Kamle, Jayant Giri, Vivek Korde(2018), "Design and evaluation of a Lean Manufacturing framework using Value Stream Mapping (VSM) for a plastic bag manufacturing unit" Materials Today: Proceedings 5 ,7668-7677.

[7] Neha Verma, Vinay Sharma(2017), "Sustainable competitive advantage by implementing lean manufacturing"A Case study for Indian SME" Materials Today: Proceedings 4 (2017) 9210-9217.

[8] Rahul Adepu, Sharan Chandran M, Satish Babu K (2015), "Application of Value Stream Mapping tool for waste reduction in manufacturing industry" International Journal of Engineering and Technical Research,ISSN: 2321-0869, Volume-3, Issue-5.

[9] Aravinth Kumar A, Janagiraman R, Rajenthirakumar D, Sathishkumar K(2016)," Lean Operational Principles and Practices Effecting in a Manufacturing Concern, International Journal of Innovative Research in Science, Engineering and Technology, ISSN(Online) : 23198753, Vol. 5, Issue 7.

[10] Satish Tyagi, Alok Choudhary, Xianming Cai, Kai Yang (2014), "Value stream mapping to reduce the leadtime of product development process" Int. J. Production Economics,S0925-5273(14)00352-1.

[11] Aravinth kumar A, Senthil Prabhu N, Rajenthirakumar D,Parthiban A (2018), "Systematic Lean Approach and Its Improvements Iin a Manufacturing Assembly Line" Int. Journal of Management, Technology And Engineering, ISSN NO : 2249-7455, Volume 8, Issue XII, Page No: 4616 -4623.

[12] Aravinth Kumar A, Rajenthirakumar D (2016), "Reducing the Manufacturing Lead Time of Export Pump Components in an Indian Pump Industry" National Journal of Technology, ISSN NO:0973-1334. 